\title{
Deteksi Molekuler Virus Dengue dan Chikungunya pada Nyamuk Aedes spp. di Kecamatan Cilongok
}

\section{Dwi Iva Fitriana*, Endang Srimurni Kusmintarsih, Trisnowati Budi Ambarningrum}

\author{
Fakultas Biologi, Universitas Jenderal Soedirman \\ Jalan dr Suparno 63 Purwokerto 53122 \\ Email: dwiivafitriana@gmail.com
}

\begin{abstract}
Rekam Jejak Artikel:
Diterima : 29/08/2019

Disetujui : 29/05/2020
\end{abstract}

\begin{abstract}
Cilongok sub-district is one of the dengue and chikungunya endemic area in Banyumas regency. Virus detection in mosquitoes before infecting humans is an early warning to prevent outbreaks in endemic areas. The purposes of this study ware to determine dengue and chikungunya virus infections in Aedes spp from Cilongok sub-district. This study was conducted in four villages (Cilongok, Pernasidi, Kalisari, and Jatisaba) in Cilongok sub-district. The research design was purposive random sampling study. Reverse-Transcriptase Polymerase Chain Reaction (RT-PCR) technique was carried out to detect dengue and chikungunya viruses in mosquitoes. The positive result analyzed descriptively to estimate potential of virus transmissions. The result showed that Aedes spp. mosquitoes in this study was negative in both dengue and chikungunya virus.

Keywords : Aedes spp., chikungunya virus, dengue virus, RT-PCR technique
\end{abstract}

\begin{abstract}
Abstrak
Kecamatan Cilongok merupakan salah kecamatan endemis DBD dan pernah mengalami KLB chikungunya. Deteksi virus pada nyamuk sebelum menginfeksi manusia penting sebagai peringatan dini dalam upaya pencegahan wabah di daerah endemis. Tujuan penelitian ini adalah mengetahui infeksi virus Dengue dan Chikungunya pada nyamuk Aedes spp. asal kecamatan Cilongok. Penelitian ini dilakukan di empat desa di Kecamatan Cilongok yang meliputi Desa Cilongok, Pernasidi, Kalisari, dan Jatisaba. Desain penelitian ini adalah studi purposive random sampling . Deteksi virus Dengue dan Chikungunya pada nyamuk dilakukan menggunakan teknik Reverse-Transcriptase Polymerase Chain Reaction (RT-PCR). Hasil positif virus dianalisis secara deskriptif untuk menggambarkan potensi transmisi virus. Hasil penelitian menunjukkan bahwa nyamuk Aedes spp. yang tertangkap tidak mengandung virus Dengue dan Chikungunya. Kata kunci: Aedes spp., chikungunya virus, dengue virus, teknik $R T-P C R$
\end{abstract}

\section{PENDAHULUAN}

Demam berdarah dengue (DBD) merupakan penyakit tropik yang disebabkan oleh virus Dengue (DENV). Virus ini terdiri dari empat serotipe, yaitu DENV1, DENV2, DENV dan DENV4. Penyakit DBD ini ditularkan melalui gigitan nyamuk Aedes aegypti (Ae. aegypti) dan Aedes albopictus (Ae. albopictus) (Pusat Data Surveilans dan Epidemiologi Kementerian Kesehatan RI, 2010). Kedua nyamuk ini juga menjadi vektor penyakit menular chikungunya yang disebabkan virus Chikungunya (CHIKV). CHIKV termasuk reemerging virus disease dan sering menyebabkan kejadian luar biasa (KLB) di berbagai negara di kawasan Asia, termasuk Indonesia (Maha \& Subangkit, 2014). Kecamatan Cilongok merupakan salah satu kecamatan yang dilaporkan endemis DBD di Kabupaten Banyumas (Widiati \& Lasmiati, 2015). Pada tahun 2009 terjadi KLB chikungunya dengan jumlah penderita rata-rata 50 orang setiap desa (BNC, 2009). Kecamatan Cilongok memiliki cuaca tidak stabil dan curah hujan yang cukup tinggi pada musim penghujan, sehingga berpotensi untuk perkembangbiakan nyamuk Aedes spp. (Dinas Kesehatan Kabupaten Banyumas, 2015).

Belum adanya vaksin DBD dan pengobatan spesifik demam chikungunya menyebabkan pengendalian vektor nyamuk Ae. aegypti dan Ae. albopictus merupakan cara yang tepat untuk mencegah persebaran kedua wabah penyakit tersebut (Suriptiastuti, 2016; Mahmud et al., 2018). Informasi keberadaan virus DENV dan CHIKV pada vektor juga diperlukan sebagai upaya dini pencegahan wabah. Informasi ini dapat memberi gambaran risiko penularan virus pada nyamuk sebelum menginfeksi manusia. Keberadaan virus DENV dan CHIKV pada vektor dapat dideteksi dengan teknik Reverse Transcriptase-Polymerase Chain Reaction (RT-PCR) (Macedo et al., 2013). Teknik RT-PCR juga dapat digunakan untuk mendeteksi serotipe virus DENV dan CHIKV yang sedang bersirkulasi di suatu wilayah. Informasi ini dibutuhkan dalam mengontrol dan mencegah DBD serta Sindrom Syok Dengue (SSD) yang terjadi akibat infeksi oleh salah satu serotipe yang kemudian diinfeksi oleh serotipe lain (Nurfadly, 2009). Dengan demikian, penelitian ini bertujuan 
untuk mengetahui infeksi DENV dan CHIKV pada vektor nyamuk Aedes spp.yang ditangkap.

\section{MATERI DAN METODE}

Desain penelitian ini merupakan studi purposive random sampling. Sampel nyamuk Aedes spp. yang digunakan dalam penelitian ini diambil secara purposive di empat desa endemis DBD di Kecamatan Cilongok, Kabupaten Banyumas yang meliputi Desa Pernasidi, Kalisari, Jatisaba, dan Cilongok. Deteksi virus Dengue (DENV) dan virus Chikungunya (CHIKV) dilakukan di Laboratorium Genetika dan Molekuler Fakultas Biologi dan Laboratorium Riset Unsoed. Penelitian ini dilaksanakan pada bulan Maret hingga Juli 2019.

\section{Isolasi genom RNA virus}

RNA virus diisolasi dari nyamuk Aedes spp. menggunakan PureLink ${ }^{\mathrm{TM}}$ Viral RNA/DNA Mini Kit (Invitrogen, Cat. No.12280050) sesuai dengan protokol kit (Mboera et al., 2016). Prosedur isolasi diawali dengan pembuatan larutan sampel, yaitu nyamuk Aedes spp. dimasukkan ke dalam microtube (Eppendorf) 1,5 $\mathrm{mL}$, kemudian ditambahkan $200 \mu \mathrm{L}$ DEPC water dan digerus menggunakan grinder. Selanjutnya, pembuatan lysate nyamuk dibuat dengan $20 \mu \mathrm{L}$ proteinase $\mathrm{K}$, $200 \mu \mathrm{L}$ sampel, dan $200 \mu \mathrm{L}$ lysis buffer (mengandung 5,6 $\mu \mathrm{g}$ carrier RNA) dimasukkan ke dalam microsentrifuge tube $1,5 \mathrm{~mL}$ dan divortex 15 detik. Setelah homogen, larutan diinkubasi selama 15 menit pada temperatur $56{ }^{\circ} \mathrm{C}$ dan disentrifugasi dengan kecepatan rendah. Lysate ditambahkan dengan $250 \mu \mathrm{L}$ etanol absolut dan di-vortex selama 15 detik. Lysate tersebut kemudian diinkubasi selama 5 menit pada temperatur ruang $\left(25^{\circ} \mathrm{C}\right)$ dan disentrifugasi dengan kecepatan rendah. Lysate dimasukkan ke dalam viral spin column bersama collection tube dan disentrifugasi dengan kecepatan $6.800 \times \mathrm{g}$ selama satu menit pada temperature ruang. Tahapan selanjutnya adalah pencucian I dilakukan dengan cara collection tube dilepas dan viral spin column dipasangkan pada wash tube baru, kemudian $500 \mu \mathrm{L}$ wash buffer ditambahkan ke dalam viral spin column bersama wash tube baru tersebut dan disentrifugasi dengan kecepatan 6.800 $\times \mathrm{g}$ selama 1 menit pada temperatur ruang. Larutan dalam wash tube dibuang. Tahap pencucian I diulang sekali dan larutan dalam wash tube dibuang dan viral spin column dipasang pada wash tube baru dan disentrifugasi dengan kecepatan 13.000 $\times \mathrm{g}$ selama 1 menit pada temperatur ruang. Larutan sisa wash buffer pada wash tube dibuang, kemudian viral spin column dipasangkan pada recovery tube 1,5 mL dan $50 \mu \mathrm{L}$ RNAse free-water ditambahkan pada viral spin column bersama recovery tube tersebut dan diinkubasi selama 1 menit pada temperatur ruang. Setelah inkubasi, larutan disentrifugasi dengan kecepatan $13.000 \times$ g selama
1 menit pada temperatur ruang. Kemudian sebanyak $25 \mu \mathrm{L}$ RNAse free-water ditambahkan pada recovery tube, viral spin column dibuang dan diperoleh larutan RNA viral pada recovery tube 1,5 $\mathrm{mL}$. Larutan RNA yang diperoleh disimpan pada suhu $-20{ }^{\circ} \mathrm{C}$ jangka waktu satu minggu atau $-80{ }^{\circ} \mathrm{C}$ untuk waktu lama.

\section{Sintesis cDNA}

Sintesis cDNA dilakukan menggunakan Superscript ${ }^{\circledR}$ III First-Strand Synthesis System for RT-PCR (Invitrogen) sesuai dengan protokol kit (Sriprapun et al., 2015). Tahapan sintesis cDNA yaitu $10 \mu \mathrm{L}$ mix sampel dibuat dengan komposisi yang terdiri dari $1 \mu \mathrm{L}$ primer oligo(dT), $1 \mu \mathrm{L} 10$ mM dNTP mix, dan $8 \mu \mathrm{L}$ sampel RNA. Mix sampel tersebut diinkubasi pada temperatur $65^{\circ} \mathrm{C}$ selama 5 menit dan langsung didinginkan dalam es $\left(0^{\circ} \mathrm{C}\right)$ selama 1 menit. Tahapan berikutnya adalah mix sintesis cDNA dibuat dengan komposisi yang terdiri dari $2 \mu \mathrm{L} 10 \times \mathrm{RT}$ buffer, $4 \mu \mathrm{L} 25 \mathrm{mM}$ $\mathrm{MgCl}_{2}, 2 \mu \mathrm{L}$ 0,1 M DTT, $1 \mu \mathrm{L}$ RNaseOUT ${ }^{\mathrm{TM}}(40$ $\mathrm{U} / \mu \mathrm{L})$, dan $1 \mu \mathrm{L}$ Superscript $^{\circledR}$ III RT $(200 \mathrm{U} / \mu \mathrm{L})$. Sebanyak $10 \mu \mathrm{L}$ mix sintesis cDNA ditambahkan ke dalam mix sampel dan diinkubasi pada temperatur $50 \quad{ }^{\circ} \mathrm{C}$ selama 50 menit. Reaksi dihentikan dengan melanjutkan inkubasi pada temperatur $85{ }^{\circ} \mathrm{C}$ selama 5 menit, kemudian didinginkan dalam es. Sebanyak $1 \mu \mathrm{L}$ RNase $\mathrm{H}$ ditambahkan ke dalam tube mix dan kemudian diinkubasi pada temperatur $37{ }^{\circ} \mathrm{C}$ selama 20 menit. Sebanyak $2010 \mu$ larutan cDNA yang diperoleh disimpan pada temperatur $-20{ }^{\circ} \mathrm{C}$.

\section{Deteksi DENV (1-4) dengan teknik Nested RT- PCR}

Nested PCR cDNA DENV menggunakan MyTaq $^{\text {TM }}$ HS Red Mix (Bioline, Cat. No.BIO25047) sesuai dengan protokol kit. Primer yang digunakan yaitu primer universal Dengue: D1 (5'-TCAATATGCTGAAACGCGCGAGAAACCG -3') dan D2 (5'-TTGCACCAACAGTCAATGT CTTCAGGTTC-3') yang akan menghasilkan amplikon cDNA berukuran 511 bp (Sari et al., 2012). Komposis PCR dibuat dengan volume 25 $\mu \mathrm{L}$ yang terdiri dari : $12,5 \mu \mathrm{L} 2 \mathrm{X}$ MyTaq HS Red Mix, $1 \mu \mathrm{L}$ primer forward D1 $[0,4 \mu \mathrm{M} / \mu \mathrm{L}], 1 \mu \mathrm{L}$ primer reverse D2 $1[0,4 \mu \mathrm{M} / \mu \mathrm{L}], 9,5 \mu \mathrm{L} \mathrm{ddH}_{2} \mathrm{O}$, dan $1 \mu \mathrm{L}$ template cDNA [sampel 1: 48,72 $\mathrm{ng} / \mu \mathrm{L}$; sampel 2: $48 \mathrm{ng} / \mu \mathrm{L}]$. PCR dijalankan pada kondisi : (i) predenaturasi $\left(95^{\circ} \mathrm{C}\right.$; 1 menit), (ii) amplifikasi 35 siklus yang terdiri dari denaturasi $\left(95^{\circ} \mathrm{C} ; 15\right.$ detik), annealing $\left(65^{\circ} \mathrm{C} ; 15\right.$ detik), dan ekstensi $\left(72^{\circ} \mathrm{C} ; 10\right.$ detik), (iv) post ekstensi $\left(72^{\circ} \mathrm{C} ; 5\right.$ menit); dan (v) hold $\left(4^{\circ} \mathrm{C}\right)$. Deteksi serotipe DENV menggunakan primer forward D1 dengan primer reverse spesifik serotipe virus Dengue yang terdiri dari TS1 untuk serotipe DEN-1 (5'CGTCTCAGTGATCCGGGGG-3') menghasilkan amplikon cDNA berukuran 482 bp, TS2 untuk serotipe DEN-2 (5'-CGCCACAAGGGCCATGA 
ACAG-3') menghasilkan amplikon DNA berukuran 119 bp, TS3 untuk serotipe DEN-3 (5'-TAA CATCATCATGAGACAGAGC-3') menghasilkan amplikon DNA berukuran 290 bp, dan TS4 untuk serotipe DEN-4 (5'-CTCTGTTGTCTTAAACAA GAGA-3') menghasilkan amplikon DNA berukuran 392 bp. PCR mix dibuat sesuai jumlah sampel yang akan diperiksa. Komposisi mix PCR dibuat dengan volume $25 \mu \mathrm{L}$ yang terdiri dari : 12,5 $\mu \mathrm{L} 2 \times$ MyTaq HS Red Mix, $1 \mu \mathrm{L}$ primer forward D1 [0,4 $\mu \mathrm{M} / \mu \mathrm{L}]$, primer reverse (masing-masing dari TS1TS4) $1 \mu \mathrm{L}[0,4 \mu \mathrm{M} / \mu \mathrm{L}], \mathrm{ddH}_{2} \mathrm{O} 9,5 \mu \mathrm{L}$, dan $1 \mu \mathrm{L}$ [sampel 1: 48,72 ng/ $\mu \mathrm{L}$; sampel 2: $48 \mathrm{ng} / \mu \mathrm{L}$ ] template dari amplikon cDNA tahap 1. PCR dijalankan pada kondisi yaitu (i) predenaturasi $\left(95^{\circ}\right.$ C; 1 menit; (ii) amplifikasi 35 siklus yang terdiri dari denaturasi $\left(95^{\circ} \mathrm{C} ; 15\right.$ detik), annealing (D1/TS1-TS4 55 ${ }^{\circ} \mathrm{C}$; 15 detik), dan ekstensi $\left(72^{\circ} \mathrm{C}\right.$; 10 detik); (iv) post ekstensi $\left(72^{\circ} \mathrm{C} ; 5\right.$ menit); dan (v) hold $\left(4^{\circ} \mathrm{C}\right)$. Sebanyak $10 \mu \mathrm{L}$ produk nested $\mathrm{RT}$ PCR dielektrofresis pada gel agarose 1,5\% dengan tegangan $80 \mathrm{~V}, 200 \mathrm{~mA}$ selama 47 menit.

\section{Deteksi CHIKV dengan RT-PCR}

PCR cDNA virus Chikungunya menggunakan MyTaq $^{\text {TM }}$ HS Red Mix (Bioline, Cat. No.BIO25047) sesuai dengan protokol. Primer yang digunakan yaitu primer CHICK-1 (5'ACCGGCGTCTACCCATTCATG T-3') dan CHIK-2(5'GGGCGGGTAGTCCATGTTGTAGA-

3') menghasilkan amplikon DNA berukuran $330 \mathrm{bp}$ (Sari et al., 2012). Komposis PCR dibuat dengan volume $25 \mu \mathrm{L}$ yang terdiri dari $12,5 \mu \mathrm{L} 2 \mathrm{X}$ MyTaq HS Red Mix, $1 \mu \mathrm{L}$ primer forward (CHIK1) [0,4 $\mu \mathrm{M} / \mu \mathrm{L}], 1 \mu \mathrm{L}$ primer reverse (CHIK2) $[0,4 \mu \mathrm{M} /$ $\mu \mathrm{L}], 9,5 \mu \mathrm{L} \operatorname{ddH}_{2} \mathrm{O}$, dan $1 \mu \mathrm{L}$ template cDNA [sampel 1: 48,72 ng/ $\mu \mathrm{L}$; sampel 2: $48 \mathrm{ng} / \mu \mathrm{L}$ ]. PCR dijalankan pada kondisi yaitu yaitu (i) predenaturasi $\left(95^{\circ} \mathrm{C}\right.$; 1 menit; (ii) amplifikasi 35 siklus yang terdiri dari denaturasi $\left(95^{\circ} \mathrm{C} ; 15\right.$ detik), annealing $\left(60^{\circ} \mathrm{C} ; 15\right.$ detik), dan ekstensi $\left(72^{\circ} \mathrm{C} ; 10\right.$ detik); (iv) post ekstensi ( $72^{\circ} \mathrm{C} ; 5$ menit); dan (v) hold $\left(4^{\circ} \mathrm{C}\right)$. Sebanyak $10 \mu \mathrm{L}$ produk RT-PCR dielektrofresis pada gel agarose $1,5 \%$ dengan tegangan $80 \mathrm{~V}, 200 \mathrm{~mA}$ selama 47 menit.

\section{Analisis Data}

Data hasil deteksi virus Chikungunya (CHIKV) dan serotipe virus Dengue (DENV) dianalisis secara deskriptif untuk mengetahui persentase jumlah positif serta jenis serotipe virus yang ditemukan.

\section{HASIL DAN PEMBAHASAN}

Hasil deteksi serotipe DENV baik dari nyamuk dewasa hasil tangkapan maupun nyamuk yang di-rearing untuk mengetahui adanya transmisi transovarial dari Kecamatan Cilongok dapat dilihat pada Gambar 1. Deteksi serotipe DENV dengan metode nested PCR negatif.

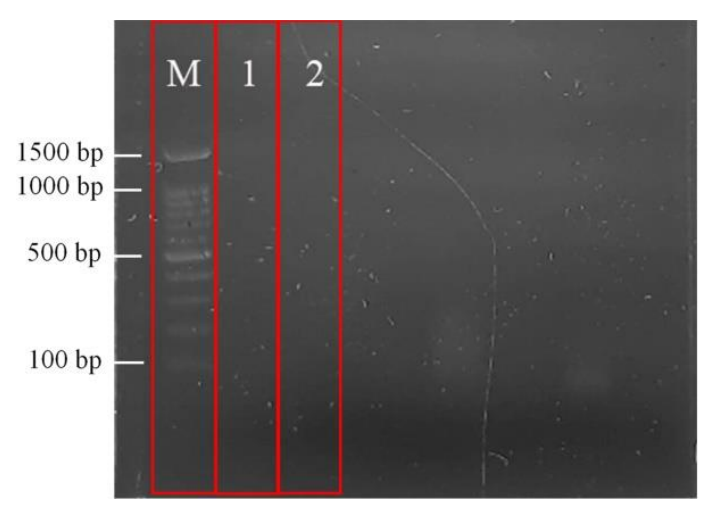

Gambar 1. Hasil deteksi serotipe Dengue pada nyamuk Aedes spp. dengan metode nestedtwo step RT-PCR.Sumuran (M) Marker DNA100-bp; (1) Sampel nyamuk Kecamatan Cilongok 1; (2) Sampel nyamuk Kecamatan Cilongok 2.

Virus Dengue (DENV) pada nyamuk tidak terdeteksi, karena virus tidak berada di dalam tubuh nyamuk. Disamping itu, konsentrasi RNA virus dalam tubuh nyamuk terlalu kecil, sehingga tidak terdeteksi saat uji PCR (Ansori et al., 2015). Hasil negatif juga dapat diakibatkan RNA virus terdegradasi selama proses penyimpanan. Degradasi menyebabkan RNA DENV pada nyamuk Aedes tidak terdeteksi. Ketahanan virus ini dalam tubuh nyamuk dipengaruhi beberapa faktor dan salah satu yang penting adalah rendah atau tingginya temperatur yang dapat menggangu ketahanan virus dalam tubuh nyamuk. Degradasi RNA menyebabkan amplifikasi cDNA tidak terjadi, sehingga serotipe virus tidak dapat dideteksi. Degradasi RNA menyebabkan amplifikasi tidak terjadi sehingga serotipe virus tidak dapat dideteksi. Selain degradasi RNA, waktu penangkapan nyamuk juga dapat mempengaruhi keberhasilan deteksi virus. Penangkapan nyamuk yang baru mengalami eklosi dari pupa (belum menghisap darah) memungkinkan diperolehnya nyamuk yang tidak mengandung virus (Fadilla et al., 2015). Penangkapan nyamuk ketika tidak terjadi wabah juga dapat menyebabkan hasil deteksi virus Dengue negatif (Ansori et al., 2015). Faktor lain yang dapat menyebabkan hasil negatif deteksi virus Dengue adalah metode yang digunakan. Penelitian transmisi transovarial virus Dengue di Banyumas yang dilakukan oleh Wijayanti et al. (2017) menggunakan dua metode yang berbeda, yaitu immunohistochemistry assay (IHC) dan one step RT-PCR menunjukkan hasil yang berbeda. Hasil sampel Ae. aegypti yang dilakukan dengan deteksi IHC positif namun setelah diuji Kembali dengan RT-PCR karena RTPCR hasilnya negatif.

Deteksi virus pada nyamuk dapat digunakan untuk mengetahui adanya transmisi transovarial virus (Purnama et al., 2017), digunakan sebagai peringatan dini pencegahan wabah DBD dan 
chikungunya di suatu daerah (Macedo et al., 2013; Morrison, 2014). Deteksi virus pada nyamuk juga dapat menduga potensi penularan virus tersebut pada manusia (Rohani et al., 2005), serta deteksi serotipe DENV secara rutin di suatu wilayah dapat digunakan untuk memprediksi kemungkinan adanya persebaran wabah (Agustiningtyas \& Lusiyana, 2017). Deteksi serotipe virus penting karena dapat terjadi infeksi sekunder yang disebabkan oleh serotipe berbeda dan dapat menimbulkan SSD. Demikian pula infeksi yang disebabkan oleh dua serotipe atau lebih pada satu individu (infeksi ganda) dan dapat menyebabkan infeksi yang semakin parah (Ansori et al., 2015). Berdasarkan hasil penelitian sebelumnya, serotipe yang paling dominan yang sering menjadi penyebab DBD di Provinsi Jawa Tengah adalah DENV-3 (Prasetyowati \& Nusa, 2012; Kusmintarsih et al., 2018).

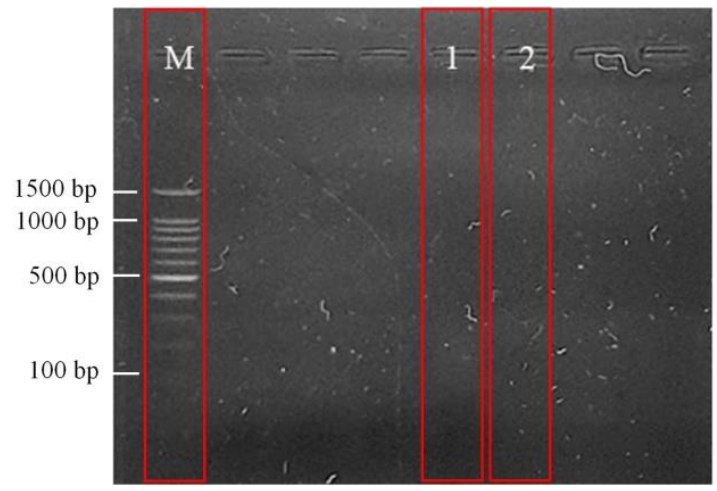

Gambar 2. Hasil deteksi CHIKV pada nyamuk Aedes spp. dengan metode two step RT-PCR pada gel agarose 1,5\%. Sumuran (M) Marker DNA100bp; (1) Sampel nyamuk Kecamatan Cilongok 1; (2) Sampel nyamuk Kecamatan Cilongok 2.

Hasil deteksi virus Chikungunya (CHIKV) pada 2 lungkang (pool) nyamuk dari empat desa negatif (Gambar 2). Berdasarkan hasil PCR tersebut, CHIKV diduga tidak ditemukan di dalam tubuh nyamuk dari lokasi penelitian (Ansori et al., 2015). Hasil yang berbeda diperoleh oleh Farraudière et al. (2017), deteksi CHIKV dengan metode qRT-PCR pada nyamuk Ae. aegypti betina di Martinique selama terjadi wabah 2013-2014 menunjukkan hasil positif serta hasil negatif pada nyamuk betina yang di-rearing dari pupa. Hasil positif CHIKV pada nyamuk Ae. aegypti juga diperoleh oleh Zayed et al. (2012) pada masa wabah di Al Hodaya Yemen tahun 2011. Deteksi CHIKV dari nyamuk Ae. aegypti dan Ae. albopictus jantan di Thailand ketika wabah tahun 2008-2009 juga positif (Thavara et al., 2009). Hasil yang berbeda dapat disebabkan oleh pengambilan sampel nyamuk pada waktu yang berbeda, hasil positif CHIKV pada penelitian Thavara et al. (2009), Zayed et al. (2012), dan Farraudière et al.
(2017) diperoleh ketika sampel nyamuk diambil pada waktu terjadinya wabah, sementara pengambilan sampel nyamuk dalam penelitian ini tidak pada waktu terjadinya wabah. Selain itu RNA CHIKV diduga tidak ditemukan dalam tubuh nyamuk (Ansori et al., 2015). untuk memberikan gambaran yang lebih komprehensip perlu ditambahkan sampel nyamuk yang lebih banyak dari kecamatan Cilongok, sehingga potensi nyamuk terdeteksi DENV dan CHIKV semakin tinggi serta perlu dilakukan deteksi virus dengan metode yang lebih sensitif seperti realtime RT-PCR.

\section{SIMPULAN}

Berdasarkan deteksi molekuler menggunakan metode RT-PCR, nyamuk Aedes spp. yang ditangkap di Kecamatan Cilongok tidak mengandung virus Dengue dan Chikungunya.

\section{DAFTAR REFERENSI}

Agustiningtyas, I. \& Lusiyana, N. 2017. Ovitrap Survey and Serotype Identification of Dengue Virus on Aedes sp Mosquito in Potorono, Banguntapan, Bantul, Indonesia. International Journal of Mosquito Research, 4(5), pp. 32-37.

Ansori, A., Sucipto, T., Deka, P., Ahwanah, N., Churrotin, S., Kotaki, T. and Soegijanto, S. 2015. Differences of Universal and Multiplex Primer for Detection of Dengue Virus from Patients Suspected Dengue Hemorrhagic Fever (DHF) in Surabaya. Indonesian Journal of Tropical and Infectious Disease, 5(6), pp.147-151.

Banyumas News.Com (BNC). 2009. Ribuan Warga Cilongok Terjangkit Chikungunya, Satu Meninggal. [online] Available at: https://banyumasnews.com/7972/ribuanwarga-cilongok-terjangkit-chikungunyasatu-meninggal/[Accessed 10 August 2019].

Dinas Kesehatan Kabupaten Banyumas. 2015. Profil kesehatan kabupaten Banyumas. Banyumas: Dinas Kesehatan Kabupaten Banyumas.

Fadilla, Z., Hadi, U.K. \& Setiyaningsih, S. 2015. Bioekologi Vektor Demam Berdarah Dengue (DBD) Serta Deteksi Virus Dengue pada Aedes aegypti (Linnaeus) dan Ae. albopictus (Skuse) (Diptera: Culicidae) di Kelurahan Endemik DBD Bantarjati, Kota Bogor. Jurnal Entomologi Indonesia, 12(1), p. 31.

Farraudière, L., Sonor, F., Crico, S., Étienne, M., Mousson, L., Hamel, R., Missé, D., Failloux, A.B., Simard, F. \& Yébakima, A. 2017. First Detection of Dengue and Chikungunya viruses in Natural Populations of Aedes aegypti in Martinique during the 
2013-2015 Concomitant Outbreak. Revista Panamericana de Salud Pública, 41, p. 63.

Kusmintarsih, E.S., Hayati, R.F., Turnip, O.N., Yohan, B., Suryaningsih, S., Pratiknyo, H., Denis, D. \& Sasmono, R.T. 2018. Molecular Characterization of Dengue Viruses Isolated from Patients in Central Java, Indonesia. Journal of Infection and Public Health, 11(5), pp. 617-625.

Macedo, G.A., de Araújo, J.M.G., Schatzmayr, H.G., Costa, F.A.C., de Filippis, A.M.B., Santos, F.B.D. \& Nogueira, R.M.R. 2013. Virological Surveillance for Early Warning of Dengue Epidemics in The State of Rio de Janeiro, Brazil. Transactions of the Royal Society of Tropical Medicine and Hygiene, 107(3), pp. 141-146.

Maha, M.S. \& Subangkit. 2014. Manifestasi Klinis Infeksi Virus Chikungunya pada Kejadian Luar Biasa di Indonesia. Jurnal Biotek Medisiana Indonesia, 3(1), pp. 11-16.

Mahmud, M.A.F., Mutalip, M.H., Lodz, N.A. \& Shahar, H. 2018. Study on key Aedes spp Breeding Containers in Dengue Outbreak Localities in Cheras District, Kuala Lumpur. International Journal of Mosquito Research, 5(2), pp. 23-30.

Mboera, L.E., Mweya, C.N., Rumisha, S.F., Tungu, P.K., Makange, M.R., Misinzo, G., De Nardo, P., Vairo, F. \& Oriyo, N.M. 2016. The Risk of Dengue Virus Transmission in Dar Es Salaam, Tanzania during An Epidemic Period of 2014. PLoS Neglected Tropical Diseases, 10(1), p.e0004313.

Morrison, T.E. 2014. Re-emergence of Chikungunya Virus. Journal of virology, 88(20), pp. 11644-11647.

Nurfadly, 2009. Deteksi dan Penentuan Serotipe Virus Dengue Tipe 1 dari Nyamuk Aedes aegypti dengan Menggunakan Reverse Transcriptase Polymerase Chain Reaction (RT-PCR) di Kota Medan. Tesis. Sekolah Pascasarjana Universitas Sumatera Utara, Medan.

Prasetyowati, P. \& Nusa, R. 2012. DHF Cases dominated by DEN-3 Serotype in The West Java Province. Health Science Journal of Indonesia, 3(1 Jun), pp. 23-26.

Purnama, S.G., Kardiwinata, P. \& Baskoro, T. 2017. USDI (Unit Sumber Daya Informasi). [Online] Available at: https://simdos.unud.ac.id/uploads/file_penel itian 1_dir/b3ef1c0e0703aa249103eeec774c 07f3.pdf [Accessed 10 Januari 2019].

Pusat Data Surveilans dan Epidemiologi Kementerian Kesehatan RI. 2010. Demam Berdarah Dengue di Indonesia Tahun 1968-
2009. Buletin Jendela Epidemiologi, 2, pp. $1-14$.

Rohani, A., Zamree, I., Lee, H.L. and Mustafakamal, I., Norjaiza, M.J., Kamila, D. 2005. Detection of Transovarian Dengue Virus for Field Caught Aedes aegypti And Aedes albopictus Mosquito Using C6/36 Cell Line and RT-PCR. Trop Biomed, 22, pp. 149-54.

Sari, T. F., Joharina, A. S. \& Anggraeni, Y. M. 2012. Identifikasi Serotipe Virus Dengue Pada Nyamuk Aedes aegypti Dan Aedes albopictus Di Kota Salatiga Dengan Metode $R T-P C R$. Salatiga: Balai Besar Penelitian dan Pengembangan Vektor dan Reservoir Penyakit Salatiga.

Sriprapun, M., Laosakul, C., Krajiw, S., Arunyingmongkol, K., Siriyasatien, P. \& Kulwichit, W. 2015. Time Course of Concurrent Infection with Dengue Virus Serotypes 2 and 4 Detected in Urine. Asian Biomedicine, 9(2), pp. 197-202.

Suriptiastuti, 2016. Re-emergensi Chikungunya: Epidemiologi dan Peran Vektor pada Penyebaran Penyakit. Universa Medicina, 26(2), pp. 101-110.

Thavara, U., Tawatsin, A., Pengsakul, T., Bhakdeenuan, P., Chanama, S., Anantapreecha, S., Molito, C., Chompoosri, J., Thammapalo, S., Sawanpanyalert, P. \& Siriyasatien, P. 2009. Outbreak of Chikungunya Fever In Thailand and Virus Detection In Field Population of Vector Mosquitoes, Aedes aegypti (L.) and Aedes albopictus Skuse (Diptera: Culicidae). Southeast Asian JTrop Med Public Health, 40(5), pp. 951-962.

Widiati \& Lasmiati. 2015. Beberapa Aspek Entomologi Pendukung Meningkatnya Kasus. Jurnal Ekologi Kesehatan, 14(4), pp. 309-317.

Wijayanti, S.P.M., Anandari, D. \& Maqhfiroch, F.A. 2017. Vertical Transmission of Dengue Virus on Field Mosquitoes in Banyumas Regency, Central Java, Indonesia. International Journal of Public Health and Clinical Sciences, 4(3), pp. 109-119.

Zayed, A., Awash, A.A., Esmail, M.A., AlMohamad, H.A., Al-Salwa, M, Al-Jasari, A., Medhat, I., Morales-Betoulle, M. dan Mnzava, A. 2012. Detection of Chikungunya Virus in Aedes aegypti during 2011 Outbreak in Al Hodayda, Yemen. Acta Tropica, 123, pp. 62-66. 